\title{
ÉTICA DEL ODONTÓLOGO EN LA PANDEMIA DEL COVID-19
}

\section{Dentist ethics in the COVID-19 pandemic}

\author{
Revelo Grace $^{1 \mathrm{a}}$ \\ ${ }^{1}$ Especialista en Estomatología Pediátrica, Especialista en Ortodoncia y Ortopedia Maxilar. \\ a Docente, Universidad Central del Ecuador; Candidata al Doctorado en Bioética Universidad El Bosque. \\ DOI: $\underline{\text { https://doi.org/10.31984/oactiva.v6i3.560 }}$
}

\section{Resumen}

La pandemia por el COVID-19 cambió la atención odontológica sustancialmente. Los procedimientos electivos fueron cancelados y se limitó a la atención exclusiva de urgencias y emergencias odontológicas con la finalidad de proteger a la comunidad del contagio por el virus y evitar su propagación. Las sociedades científicas a nivel mundial han brindado diversos documentos para la atención odontológica con base en los lineamientos dados por la Organización Mundial de la Salud, sin embargo, la literatura sobre la actitud ética del odontólogo durante la pandemia es limitada.

Palabras clave: ética, bioética, ética odontológica, infecciones por coronavirus, atención odontológica.

\section{Summary}

The COVID-19 pandemic changed dental care substantially. The elective procedures were canceled and were limited to the exclusive care of emergencies and dental emergencies to protect the community from contagion by the virus and prevent its spread. Scientific societies worldwide have provided various documents for dental care based on the guidelines given by the World Health Organization, however, the literature on the ethical attitude of the dentist during the pandemic is limited.

Key words: ethics, bioethics, dental ethics, coronavirus infections, dental care.

\section{Introducción}

Los coronavirus (CoV) son una familia de virus que producen enfermedades que van desde el resfriado común hasta enfermedades más graves. La epidemia de COVID-19 fue declarada por la Organización Mundial de la Salud (OMS) como una emergencia de salud pública de preocupación internacional el 30 de enero de 2020(1). El Director General de la OMS, Doctor Tedros Adhanom Ghebreyesus, hizo un llamado para que todos los países se preparen para la contención, la vigilancia activa, la detección temprana, el aislamiento y el manejo de casos, rastreo de contactos y prevención de la propagación por el COVID-19, además, llamó a la comunidad internacional para apoyar a los países de bajos y medianos ingresos para permitir su respuesta al evento $^{(2)}$. El 11 de marzo de 2020 el Director General de la OMS declaró el COVID-19 como una pandemia y enfatizó que el término pandemia no debe usarse a de manera inadecuada porque puede provocar un miedo irracional o generar una idea injustificada de que la lucha ha finalizado. ${ }^{(3)}$
COVID-19 ha producido grandes cambios en la odontología, aunque los odontólogos se encuentran familiarizados con enfermedades como la hepatitis B y hepatitis C y la evaluación de los riesgos ${ }^{(4)}$, la atención odontológica implica un contacto cercano con el paciente y la generación de aerosoles con partículas virales. El New York Times indicó que la odontología es la profesión con mayor riesgo de contraer COVID-19 por la cercanía que tiene con el paciente. ${ }^{5)}$ Para minimizar los riesgos de infección por el COVID-19 se han generado diversos protocolos y guías para su atención. En la página web de la World Dental Federation se encuentran varios documentos sobre información general del COVID-19, guías de tratamiento y prácticas dentales durante la pandemia de COVID-19, los recursos para financiamiento y apoyo para odontólogos, recursos para el paciente y otros recursos ${ }^{(6)}$. La biblioteca Cochrane ofrece guías brindadas por diversas comunidades académicas odontológicas a nivel mundial para el equipo 
de salud dental y oral ${ }^{(7)}$. Las guías para el equipo de salud oral son sobre los equipos de protección personal, las indicaciones para la atención de pacientes durante la pandemia, prevención y control de infecciones en la práctica odontológica, recomendaciones para los pacientes, etc.

Al iniciar la pandemia, el Ministerio de Salud del Ecuador limitó la atención odontológica de rutina mientras dure la emergencia sanitaria a la realización exclusiva de tratamientos de emergencias y urgencias odontológicas definidas en el documento normativo con la finalidad de proteger a la comunidad del contagio con el COVID-19(8). La literatura sobre la ética del odontólogo durante la pandemia es limitada ${ }^{(9)}$. Este artículo revisa la literatura sobre las publicaciones relacionadas con la ética odontológica durante la pandemia por el COVID-19.

\section{Estado del arte}

\section{Toma de decisiones en odontología durante la pandemia} del COVID-19

Según Coulthard ${ }^{(10)}$ en el Reino Unido al iniciar la pandemia del COVID-19 los Servicios de Salud Nacional permitieron la atención odontológica de rutina de pacientes asintomáticos, sin embargo, muchos odontólogos sintieron el deber moral de reducir las atenciones de rutina. La primera responsabilidad moral es salvar vidas y los trabajadores de la salud tienen la obligación moral de cuidar los pacientes. Al iniciar la pandemia los casos de pacientes asintomáticos y posiblemente infectados aumentaban y para su atención los odontólogos no usaban los elementos de protección como guantes, mascarillas y protectores oculares por la falta de disponibilidad. El Doctor Coulthard como Decano de la Facultad de Odontología, suspendió la atención de pacientes por los estudiantes, esta decisión fue tomada en base a la teoría de que la exposición a las altas cargas virales del equipo médico en China estaba relacionada con la severidad de la enfermedad y las muertes de médicos y estudiantes de medicina publicadas en la prensa, pero no en la literatura científica. Además, escribió un artículo donde expresaba su opinión a los Cirujanos Maxilofaciales sobre el cuidado durante la atención odontológica. Aunque su decisión no seguía las directrices de los Servicios de Salud Nacional, sintió que moralmente estaba justificada la recomendación de realizar procedimientos de urgencias durante la pandemia usando los elementos de protección personal para el control de contagio y reducir el contacto con los pacientes ${ }^{(10)}$.

Ante la pregunta sobre cuáles son las responsabilidades éticas del odontólogo durante la pandemia los Miembros del Subcomité de Ética de la Asociación Dental Americana plantearon que, aunque existe un Código de Ética Odonto- lógico, las obligaciones éticas durante circunstancias de emergencia pueden cambiar para el bien común, siendo probable que se deba practicar el distanciamiento social o revelar la información del paciente. Cuando se aplazan o suspenden procedimientos electivos se está protegiendo al paciente y la comunidad del coronavirus por la reducción de aerosoles producidos en las consultas por las piezas de mano de alta velocidad y la limpieza por profilaxis o ultrasonido, esta decisión se encuentra respaldada por los principios de no maleficencia, beneficencia y justicia. Al participar en el distanciamiento social disminuyendo el contacto entre los pacientes y los miembros del personal se limita el riesgo de daño a los pacientes, a los miembros del personal y al odontólogo. Estos esfuerzos contribuyen en el "aplanamiento" de la curva. Cuando se requiere la atención de urgencias se deben emplear los elementos de protección personal, en caso de quedarse sin ellos se tiene la obligación de suspender el servicio(11).

Por motivos financieros, algunos odontólogos continuaron la práctica clínica para pagar a sus empleados, sin embargo, esto puede traer riesgos para la salud del equipo odontológico y la salud de la comunidad en general. La obligación ética de "actuar en beneficio de los otros" debe ser la prioridad, aunque signifique limitar temporalmente el servicio. Durante la pandemia por el COVID-19 se debe buscar promover el mayor bien para el mayor número, el principio de Beneficencia protege la prestación de servicios de urgencias y emergencias de tal manera que el odontólogo realice lo necesario para el mejor interés de la sociedad ${ }^{(11)}$

La evidencia mínima o ausente sobre el comportamiento de virus justifica que el odontólogo ayude a salvar la vida de los pacientes manteniendo la atención exclusiva de urgencias y emergencias. El respeto mutuo de los involucrados y la limitación del daño se refieren a lo colectivo y no solo a lo individual, por ello, durante una pandemia es posible que el odontólogo deba pasar por alto protocolos en beneficio del paciente, pero también debe considerar otros principios éticos. Estas desviaciones de la norma implican que los marcos éticos deban cambiar en situaciones de pandemia ${ }^{(9)}$.

$\mathrm{D}^{\prime} \mathrm{Cruz}^{(12)}$ ejemplifica uno de los escenarios que suceden durante la pandemia. El caso es una paciente de 76 años que llama por presentar un fuerte dolor a nivel del tercer molar inferior izquierdo, el diente tiene una restauración provisional fracturada que fue realizada para calmar el dolor mientras llegaba el día de la extracción dental programada en el hospital porque la paciente consume bifosfonatos y por ello requiere el tratamiento intrahospitalario. El tratamiento que necesita es una restauración con ionómero de vidrio, sin embargo, esto no se encuentra dentro de los parámetros de urgencia, además, el odontólogo no cuenta con los elementos de protección personal para la atención. 
La reflexión y el análisis del caso presentado plantea el escenario inicialmente para el odontólogo y después para el paciente ya que es instintivamente incorrecto razonar en un foco centrado en el paciente. Durante una pandemia el personal de la salud debe seguir la premisa de la autoconservación, si el personal de la salud contrae el virus no podrá hacer el trabajo crucial en el que está capacitado y es experto en hacer. El lenguaje adoptado por los medios de comunicación hace de la pandemia una "guerra" contra el virus, una "batalla" para salvar vidas y quienes trabajan ocupan su lugar en "primera línea". Los soldados se inscriben en la "primera línea" con la expectativa de ponerse en peligro como parte de su trabajo remunerado, en cambio, el personal de la salud no hace su trabajo para arriesgar su propia vida sino para salvar a los demás. El lenguaje de la guerra coloca a los trabajadores de la salud en una posición ética peligrosa, la caracterización de ellos como "héroes" ejerce una presión moral, emocional y psicológica para que asuman riesgos que de otro modo no hubieran hecho, trabajando horas sin descanso y sin el equipo de protección personal adecuados ${ }^{(12)}$.

El análisis del escenario desde la perspectiva del paciente tiene en consideración que la paciente tiene 76 años, está bien y toma bifosfonatos, ella está en una lista de espera para la extracción en un hospital y solo necesita la restauración provisional para aliviar el dolor, en circunstancias normales ella asistiría a la atención y el trabamiento se realizaría en menos de media hora. Durante la pandemia una estrategia del gobierno es el distanciamiento social, ella no debería salir de casa, es vulnerable al virus y si lo contrae implicaría el uso previamente evitable de recursos finitos como los ventiladores, elementos de protección personal más costosos, camas, diagnóstico y personal poniendo su salud en riesgo. Por lo anterior, no se trata sólo de lo que es mejor para el paciente. Brindar atención en salud ética en beneficio del paciente es complejo ya que existe un equilibrio muy delicado para acertar ${ }^{(12)}$.

\section{Discusión}

El odontólogo durante la pandemia del COVID-19 se enfrenta al dilema ético de entre tratar o no tratar al paciente, además, a la angustia ética de contraer el equipo odontológico y el paciente la infección por el virus. El Ministerio de Salud del Ecuador recomienda para la atención odontológica que todo paciente debe tratarse como paciente de alto riesgo y potencialmente sospechoso para COVID-19, el uso de herramientas tecnológicas como la teleodontología para la anamnesis, la reducción de tiempo operatorio y aplicar un tiempo mínimo de 10 minutos entre paciente y paciente para ventilar el ambiente antes de una nueva atención $^{(13)}$. Por lo tanto, el riesgo del paciente para contraer la infección por el virus al asistir a la consulta odontológica debe contemplarse en el Consentimiento Informado, teniendo en cuenta que cada cita que el paciente acude existe la probabilidad de contagio.

Otros dilemas que traen las restricciones para la atención odontológica es que se pueden afectar y agudizar las condiciones odontológicas del paciente como el cáncer oral ${ }^{(14)}$. La decisión de brindar atención al paciente debe basarse en la seguridad del paciente, las facilidades de adoptar un sistema de referencia y de emergencias buscando proteger los pacientes ${ }^{(15)}$. La educación del paciente, seguir los protocolos de control de infecciones, contar con los elementos de protección personal son estrategias para considerar atender al paciente.

Es fundamental que, en el caso de los niños, adolescentes y otras personas vulnerables los representantes legales otorguen el consentimiento informado determinando si el riesgo-beneficio es aceptable para la realización de un procedimiento, especialmente, en casos de procedimientos invasivos. Además, debe explicársele al niño el procedimiento en un lenguaje sencillo y solicitar el asentimiento informado ${ }^{(16)}$.

La teleodontología es una herramienta que puede emplearse para continuar la comunicación con el paciente a través de llamada telefónica, mensajes electrónicos y videoconferencia. Al realizar la consulta virtual es fundamental mantener una comunicación efectiva, manejando un tono de voz amable, pausado, calmado y de confianza. Se debe brindar atención a la información que el paciente le proporciona, mostrando empatía y brindando seguridad de que se buscará una solución para la situación del paciente ${ }^{(17)}$.

Quedan varias incógnitas sobre la mejor evidencia sobre la ética del odontólogo en situaciones de pandemia, además, se debe considerar las diferencias entre los contextos de salud de los países desarrollados y los que están en vías de desarrollo lo que implica que en ciertos casos no puede universalizarse la toma de decisiones debido a las particularidades del sistema de salud de cada país. Se recomienda contar con un nuevo marco ético apropiado para la pandemia.

\section{Conclusión}

La responsabilidad ética del odontólogo durante la pandemia del COVID-19 consiste en seguir las medidas adoptadas por el Ministerio de Salud de cada país. Los principios de beneficencia, no maleficencia y justicia justifican la limitación de la actividad odontológica y el aplazamiento de procedimientos electivos. La comunidad odontológica debe estar unida, seguir con el distanciamiento social y en caso de ser necesaria la atención debe contar con los elementos de protección personal de calidad e 
informar al paciente que existe la posibilidad de contagio durante la atención. Se requiere la formulación de un marco ético contextualizado para situaciones de pandemia.

\section{Referencias}

1. Organización Panamericana de la Salud. Enfermedad por el Coronavirus (COVID-19)]. [Online]. 2020 [cited 2020 Julio 19]. Available from: HYPERLINK "https://www.paho.org/es/tag/enfermedad-por-coronavirus-covid-19" https://www.paho.org/es/tag/enfermedad-por-coronavirus-covid-19.

2. Organización Panamericana de la Salud. La OMS declara que el nuevo brote de coronavirus es una emergencia de salud pública de importancia internacional. [Online]. 2020 [cited 2020 Julio 19]. Available from: HYPERLINK "https://www.paho.org/es/notic i a s/30-1-2020-o m s - d e c 1 a ra-que-nuevo-brote-coronavirus-es-emergencia-saludpublica-importancia" https://www.paho.org/es/notic i a s / $30-1-2020-0 \mathrm{~m} \mathrm{~s}-\mathrm{d}$ e c l a ra-que-nuevo-brote-coronavirus-es-emergencia-saludpublica-importancia .

3. Organización Mundia de la Salud. Alocución de apertura del Director General de la OMS en la rueda de prensa sobre la COVID-19 celebrada el 11 de marzo de 2020. [Online]. 2020 [cited 2020 Julio 19]. Available from: HYPERLINK "https://www.who.int/es/dg/speeches/d e t a i l / w h o - d i r e c t o r - g e n e ral-s-opening-remarks-at-the-media-briefing-on-covid19---11-march-2020" https://www.who.int/es/dg/speec h e s / d e t a i l/w ho-dire c t o r - g e n e ral-s-opening-remarks-at-the-media-briefing-on-covid19---11-march-2020 .

4. Moodley R NSWJ. The prevalence of occupational health-related problems in dentistry: A review of the literature. J Occup Health. 2018; 60(2): p. 111-125.

5. Gamio L. The Workers Who Face the Greatest Coronavirus Risk. The New York Times. 2020 Marzo 15.

6. FDI World Dental Federation. FDI COVID-19 Resource Library. [Online]. 2020 [cited 2020 Julio 19]. Available from: HYPERLINK "https://www.fdiworlddental.org/fdi-covid-19-resource-library" https://www.fdiworlddental.org/fdi-covid-19-resource-library .

7. Cochrane Oral Health. COVID-19 (coronavirus): resources for the oral and dental care team. [Online].; 2020 [cited 2020 Julio 19]. Available from: HYPERLINK "https://oralhealth.cochrane.org/news/co$\mathrm{v}$ i d - 19 - c o r o n a v i r u s - r e sources-oral-and-dental-care-team" https://oralhealth.cochrane.org/news/covid-19-coronavirus-resources-oral-and-dental-care-team .

8. Ministerio de Salud del Ecuador. Documentos normativos Covid-19 Ecuador. [Online].; 2020 [cited 2020 Julio19]. Available from: HYPERLINK "https://www.salud.gob.ec/wp-content/up 1 o a d s / $2020 / 04 /$ P R O T O C O LO-PARA-ATENCI $\%$ C3\% $\% 3 \mathrm{~N}-O D O N T O L \% C 3 \% 93$ GICA-EN-EMERGENCIAS-Y-URGENCIAS-ODON TOL\%C3\%93GICAS-DURANTE-LA-EMERGENCI A-SANITARIA-POR-COVID-19.pdf" https://www.salud.gob.ec/wp-content/uploads/2020/04/PROTOCOLO-PARA-ATENCI $\%$ C3\% $\% 3 \mathrm{~N}-O D O N T O L \% C 3 \% 93$ GICA-EN-EMERGENCIAS-Y-URGENCIAS-ODON TOL\%C3\%93GICAS-DURANTE-LA-EMERGENCI A-SANITARIA-POR-COVID-19.pdf .

9. Kathree B, Khan S, Ahmed R, Maart R, Layloo N, Asia-Michaels W. COVID-19 and its impact in the dental setting: A scoping review. PLoS ONE. 2020 December; 15(12).

10. Coulthard P. Dentistry and coronavirus (COVID-19) moral decision-making. British Dental Journal. 2020; p. 503-505.

11. Ethics Subcommittee of the Council on Ethics, Bylaws and Judicial Affairs. Ethical practice during the COVID-19 pandemic. Journal of American Dental Association. 2020; 151(5): p. 377-378.

12. D'Cruz L. PPE or not PPE - that is the question. British Dental Journal. 2020; 228(10): p. 753-754.

13. Ministerio de Salud Pública del Ecuador. [Online]. 2020 [cited 2021 Enero 15]. Available from: HYPERLINK "https://www.salud.gob.ec/wp-content/up 1 o a d s / $2020 / 09 / \mathrm{R}$ e c o m e n d a ciones-para-la-atenci $\% \mathrm{C} 3 \% \mathrm{~B} 3 n$-en-odontolog $\% \mathrm{C} 3 \% \mathrm{~A}$ Da-por-la-Covid-19.pdf" https://www.salud.gob.ec/wp-content/uploads/2020/09/Recomendaciones-para-la-atenci\%C3\%B3n-en-odontolog $\% \mathrm{C} 3 \% \mathrm{~A}$ Da-por-la-Covid-19.pdf .

14. Arduino P, Conrotto D, Broccoletti R. The outbreak of Novel Coronavirus disease (COVID-19) caused a worrying delay in the diagnosis of oral cancer in north-west Italy: the turin metropolitan area experience. Oral Diseases. 2020.

15. Gaffar B, Alhumaid J, Alhareky M, Alonaizan F, Almas K. Dental Facilities During the New Corona Outbreak: A SWOT Analysis. Risk Management and Healthcare Policy. 2020 August; 13: p. 1343-1352.

16. Asociación Latinoamericana de Odontología Pediátrica. Marco bioético en la atención odontológica de pacientes pediátricos en tiempos de COVID-19. Revista de Odontopediatría Latinoamericana. 2020 Agosto; $10(2)$.

17. Asociación Latinoamericana de Odontopediatría. Teleodontología. Revista de Odontopediatría Latinoamericana. 2020 Agosto; 10(2).

Recibido: 15 de enero de 2021

Aceptado: 11 de marzo de 2021 